\title{
Remote Monitoring of the Health Status of Pregnant Women at Risk for Preeclampsia
}

\author{
Nikolay 0 Ankudinov ${ }^{1 *}$, Alexey F Sitnikov ${ }^{2}$ and Fedor A Sitnikov ${ }^{2}$ and Sergey V Martirosyan ${ }^{3}$ \\ ${ }^{1}$ Obstetrician-gynecologist of the highest category, ultrasound diagnostics doctor, head of the obstetric remote consultation \\ center of the State Budgetary Healthcare Institution of the Sverdlovsk Region "Yekaterinburg Clinical Perinatal Center, Russia \\ ${ }^{2}$ Incordmed LLC, Russian Federation, Russia \\ ${ }^{3}$ Chief Medical Officer of the State Budgetary Healthcare Institution of the Sverdlovsk Region "Yekaterinburg Clinical Perinatal Center, \\ Russia \\ *Corresponding author: Nikolay O Ankudinov, obstetrician-gynecologist of the highest category, ultrasound diagnostics doctor, head \\ of the obstetric remote consultation center of the State Budgetary Healthcare Institution of the Sverdlovsk Region "Yekaterinburg \\ Clinical Perinatal Center" Russia
}

\section{ARTICLE INFO}

Received: 慧 November 09, 2021

Published: 慧 November 12, 2021

Citation: Nikolay O Ankudinov, Alexey F Sitnikov, Fedor A Sitnikov. Remote Monitoring of the Health Status of Pregnant Women at Risk for Preeclampsia. Biomed J Sci \& Tech Res 39(5)-2021. BJSTR. MS.ID.006378.

\begin{abstract}
The article presents the practical application of telemedicine information technologies that have allowed maternity institutions of the Sverdlovsk region to carry out remote monitoring the health of patients during pregnancy with hypertension and at risk for preeclampsia.
\end{abstract}

Keywords: Information Technologies; Telemedicine; Remote Health Monitoring; Healthcare; Maternity Care; Referral; Routing; Pregnant Woman's Personal Account; Preeclampsia; Arterial Hypertension; Electronic Diary of Self-Monitoring of Health

\section{The Role of Remote Technologies in the Quality} Management System and Safety of Medical Care

On April 26, 2021, Deputy Chairman of the State Duma Irina Yarovaya at a meeting of the Presidium of the Council of Legislators of the Russian Federation under the Federal Assembly of the Russian Federation called for simplifying the exchange of data between medical institutions and patients. In the Sverdlovsk region, an automated information system of mobile notifications "AIST_SMART" for pregnant patients and doctors began to operate. Using a smartphone or, say, a tablet, pregnant patients in their personal account get the opportunity to keep an electronic diary of self-control of their health. The diary has the functions of automatic interpretation of the results and the formation of signal information for the obstetrician-gynecologist. Now pregnant women do not need to fill out paper diaries of self-control (Figure 1), call their doctor or the reception of the antenatal clinic in order to report the results - the process is fully automated.
The women's consultation received an IT tool for remote interaction with pregnant women and women in child child. The introduction of "AIST_SMART" technologies made it possible to replace paper diaries with electronic ones. Medical data of the patient are collected in a single database and allow you to track the dynamics of the patient's health around the clock. The results of electronic diaries are automatically processed by the system and if no abnormalities are detected, the data is simply recorded in the system and does not disturb the doctor (Figures 2 \& 3). In case of detection of deviations in the patient's state of health, the system marks the identified deviations and sends a notification to the doctor about the current state (Figure 4). Mobile notifications instantly convey accurate and detailed information about the patient's state of health and thus contribute to the timely decision to hospitalize in case of detection of preeclampsia / severe arterial hypertension. Remote health monitoring functions as follows. 


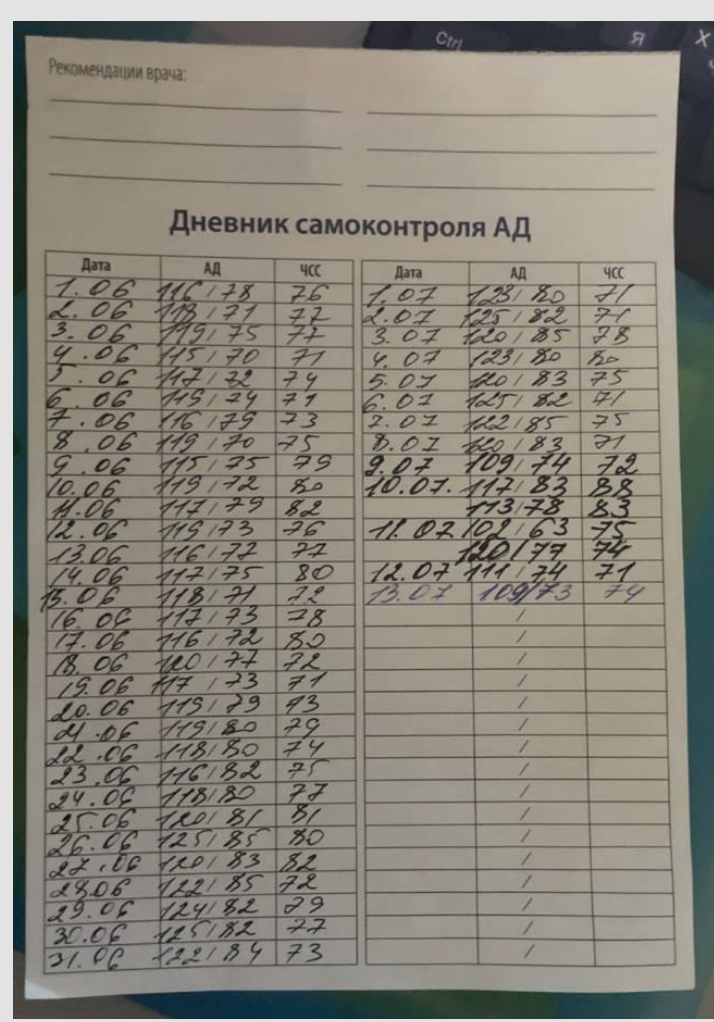

Figure 1: Paper diary - as it WAS.
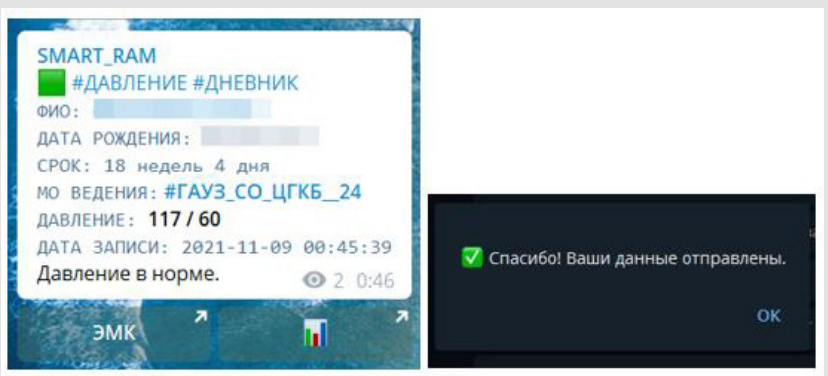

Figure 2: Data of the diary of self-control of blood pressure, the norm.

\section{Registration in the System “AIST_SMART”}

To register the patient in the personal account at the initial appointment of a pregnant patient, a consent-instruction [1] is issued to connect to the mobile service "AIST_SMART" with an individual $\mathrm{QR}$ code. At home, the patient reads the $\mathrm{QR}$ code using the camera of her smartphone or tablet and, according to the instructions, undergoes the registration procedure, forming a digital four-digit PIN-code. From now on, it is guaranteed 24/7 technical support. The QR code serves as the patient's identifier and the link between her electronic medical record (EHR) in the AIST "RAM" and the personal account in the "AIST_SMART" system. To register a doctor in your personal account, you must log in to the medical information system - AIST "RAM", in which all medical personnel of the obstetric service in the region work. Open the "Personal Account" tab and register by scanning an individual QR code. So, in order to access electronic self-control diaries, the doctor and the patient connect to the AIST_SMART service, and after registering in the system, notifications about the results of remote health monitoring will be received on their mobile device. The doctor does not need to call on the phone to find out how she feels, what her blood pressure, temperature, etc.

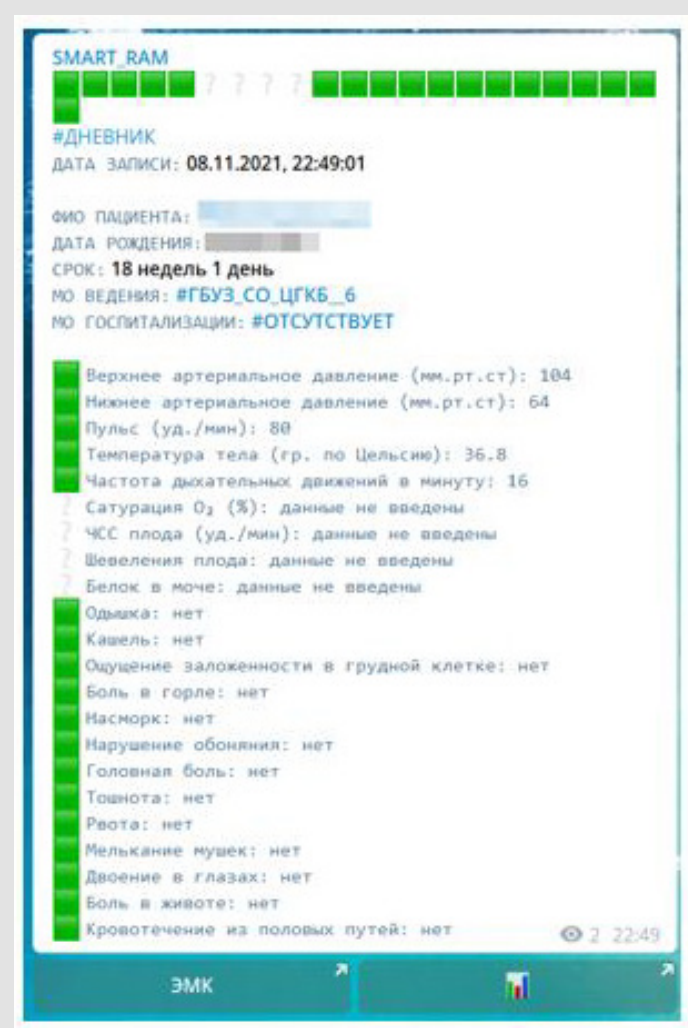

Figure 3: The data of the expanded diary of self-control, all indicators are normal.

\section{How the Mobile Alert System Works}

\section{Formation of Notification of the Result of Self-Control Diaries}

This process is fully automated. AIST_SMART performs the role of an intellectual assistant to the obstetrician-gynecologist/ midwife. The patient fills in the diary data, and the doctor receives ready-made results with automatic interpretation. Now the patient will not forget her paper diary at home, and the doctor will be able to make decisions on the tactics of management, taking into account not only the data on a face-to-face visit, but comprehensively taking into account the results of the patient's home self-control, which is important when selecting antihypertensive therapy in patients with arterial hypertension. 


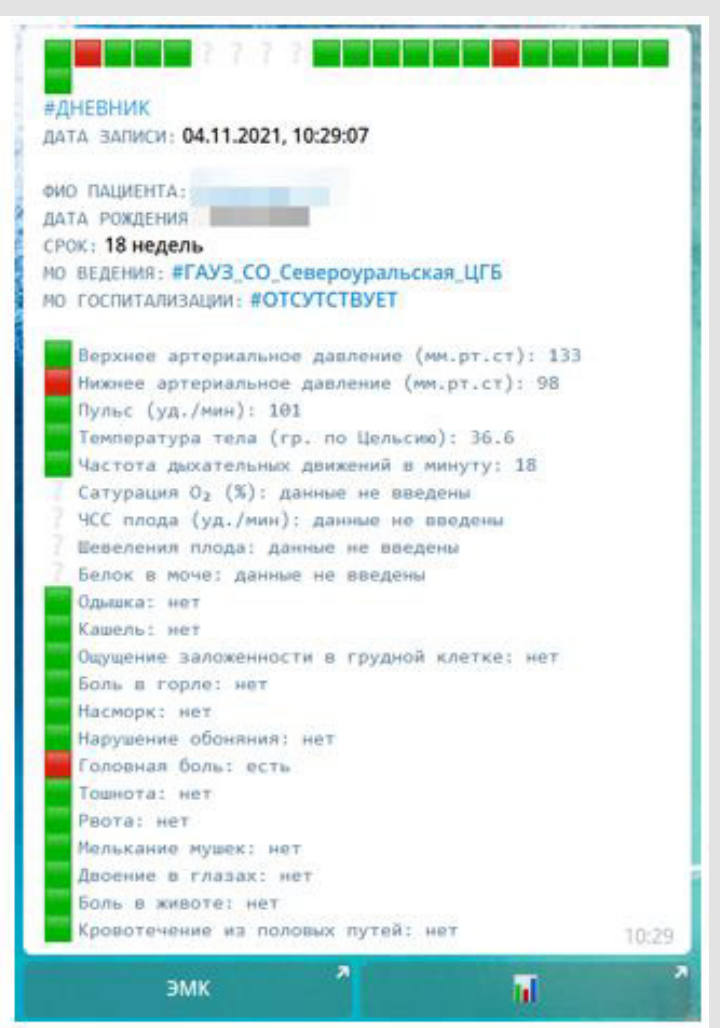

Figure 4: Data of the expanded diary of self-control with deviations of blood pressure.

\section{Pregnancy with Arterial Hypertension and at Risk for Preeclampsia}

All patients in this category should carry out home monitoring of blood pressure with keeping a diary [2]. The self-control diary can be kept both by filling out the extended web-form of the diary, and by means of a chatbot in AIST_SMART, where the patient can send data in the format of a simple message: "pressure 120 70" and the service automatically recognizes, processes the data and records them in her personal account. If deviations of blood pressure above the norm are detected, AIST_SMART will automatically offer the patient a further algorithm of actions:

\section{Indicate Complaints and the Presence of Proteinuria According to the Results of the Test Strip (Figure 5)}

\section{Emergency Hospitalization without Further Action is Recommended (Figure 6)}

All notifications in case of deviations are automatically sent to the attending physician and the doctor in the Obstetric Remote Consultation Center (hereinafter referred to as the ADCC) for the routing of the patient 24/7. Doctor of the ADC on the basis of the results of the self-control diary (Figure 7) and obstetric status according to the data in the electronic medical record (hereinafter - EHR) in the AIST "RAM", where there is information about all the results of the examination, the course of pregnancy and diagnoses, decides on further management tactics: to continue outpatient treatment or hospitalization in an obstetric hospital. The ADCC doctor fixes his decision in the EHR, making out a remote consultation for the attending physician of the antenatal clinic or obstetric hospital, if the patient is hospitalized in the MO level 1.2.

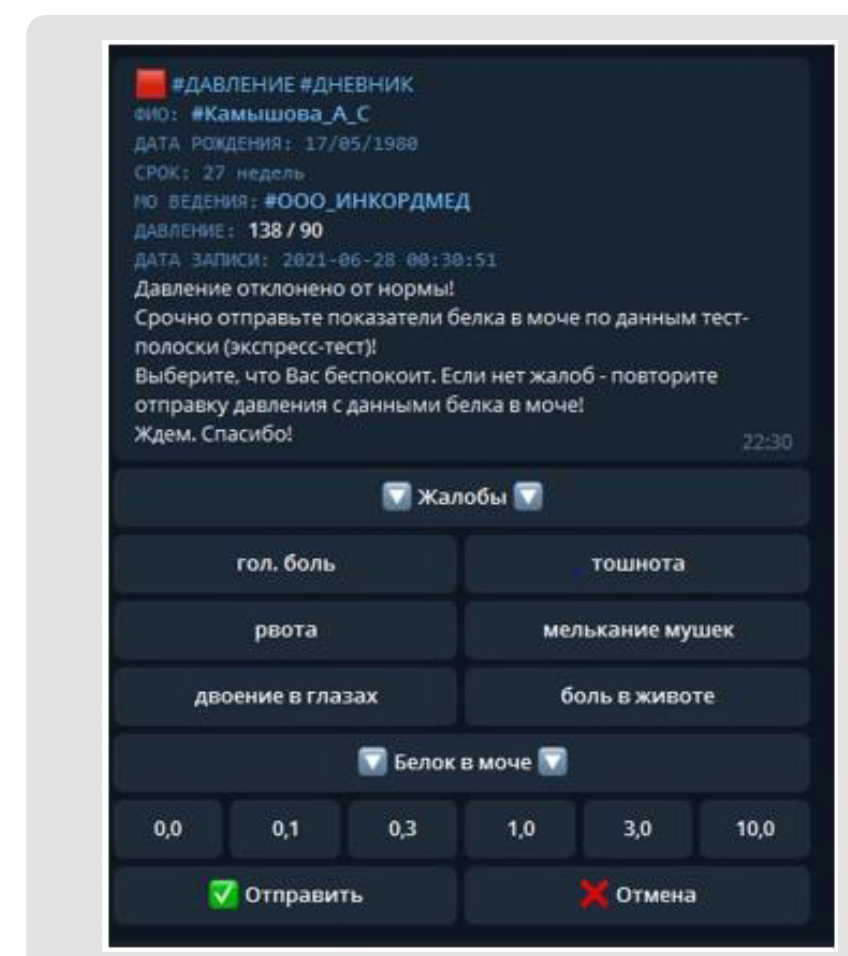

Figure 5: Algorithm of actions for the patient in the case of moderate arterial hypertension.

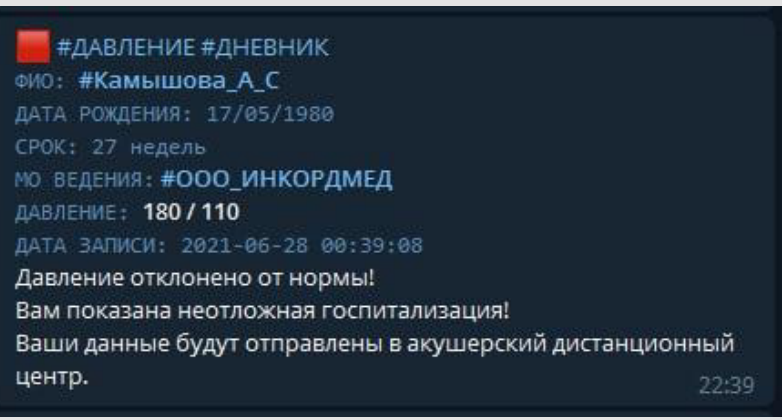

Figure 6: Algorithm of actions for the patient in the case of severe arterial hypertension.

In the absence of indications for hospitalization, the results of the remote consultation are sent automatically to the attending physician of the antenatal clinic. Subsequently, the attending physician within the framework of the next outpatient visit will be able to track the patient's condition, the effectiveness of the prescribed antihypertensive therapy, viewing trends in diaries, and adjust the therapy based on a comprehensive analysis. If a 
decision is made on the need for hospitalization, the doctor of the ADC through a confidential "working" chat in AIST_SMART can contact the patient and clarify her consent to hospitalization and the possibility of transportation by personal transport. If consent is obtained (Figure 8), the doctor of the ADCC draws up an additional referral for (re-) hospitalization to a particular obstetric hospital, taking into account the level of MO and the location of the patient.

\begin{tabular}{|c|c|c|c|}
\hline 25.09 .2021 & $16: 46: 17$ & Aртериальное давлетnе & $130 / 40$ \\
\hline 24.09 .2021 & $17: 00: 28$ & Aртериальное давление & $125 / 10$ \\
\hline 22.09 .2021 & 18.26 .27 & Артериальнсе давление & $120 / 90$ \\
\hline 22.09 .2021 & 08.29 .59 & Артериальное даелемие & $120 / 50$ \\
\hline 21.09 .2021 & 20.49 .17 & Aprepuarlonoe дaeserve & $135 / 65$ \\
\hline 21.09 .2021 & $10.54: 32$ & Aprepuanbuoe дaenerue & $120 / 90$ \\
\hline 21.09 .2021 & $10.54: 32$ & ranoereag 6anb & (ect) \\
\hline 19.09 .2021 & $20.17: 00$ & Артериальное давлемие & $125 / 60$ \\
\hline 18.09 .2021 & $12: 16: 37$ & Aprepuanonoe дaenerve & $115 / 70$ \\
\hline 17.09 .2021 & 18.38 .42 & Аpтериальное даanenue & $140 / 80$ \\
\hline 16.09 .2021 & $19.26: 04$ & Aprepuaronoe sasereme & $185 / 65$ \\
\hline 16.09 .2021 & 12.53 .00 & Apтериалоное давлетье & $120 / 80$ \\
\hline 15.09 .2021 & $11: 47: 35$ & Aртериальное давлетие & $120 / 50$ \\
\hline 14.09 .2021 & $20: 38: 53$ & Aprepuananoe даenerve & $130 / 50$ \\
\hline 13.09 .2021 & $17: 58.33$ & Aprepuantuce даaneruse & $140 / 90$ \\
\hline 13.09 .2021 & $17,58: 33$ & ranoeveas Gonb & ects \\
\hline 13.09 .2021 & $1421: 41$ & Aprepuarboнoe saenerue & $130 / 80$ \\
\hline
\end{tabular}

Figure 7: Dynamics of the state of health according to the electronic diary of self-control.

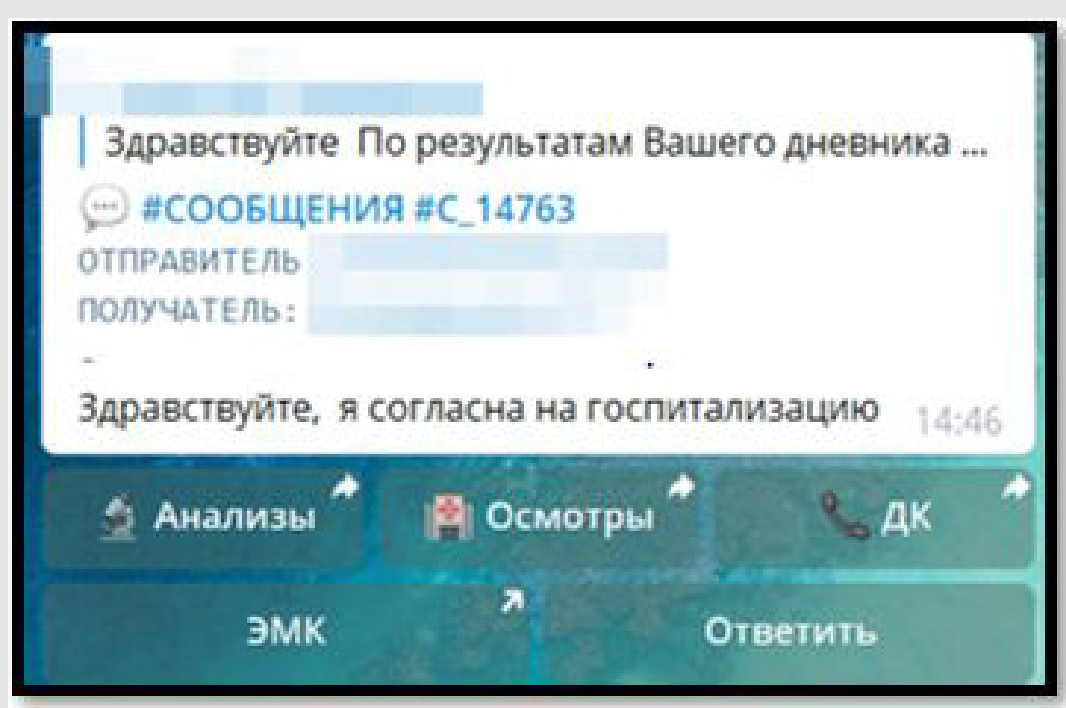

Figure 8: Communication with the patient through confidential "working" chat in AIST_SMART.

The patient receives a notification about the issued referral indicating the obstetric hospital, the date and time of hospitalization (Figure 9). In turn, the doctor of the obstetric hospital also receives information that the patient is sent to him both through the AIST "RAM" (Figure 10) and in the personal account of AIST_SMART through automatic notifications in the directions (Figures 9\&10). 


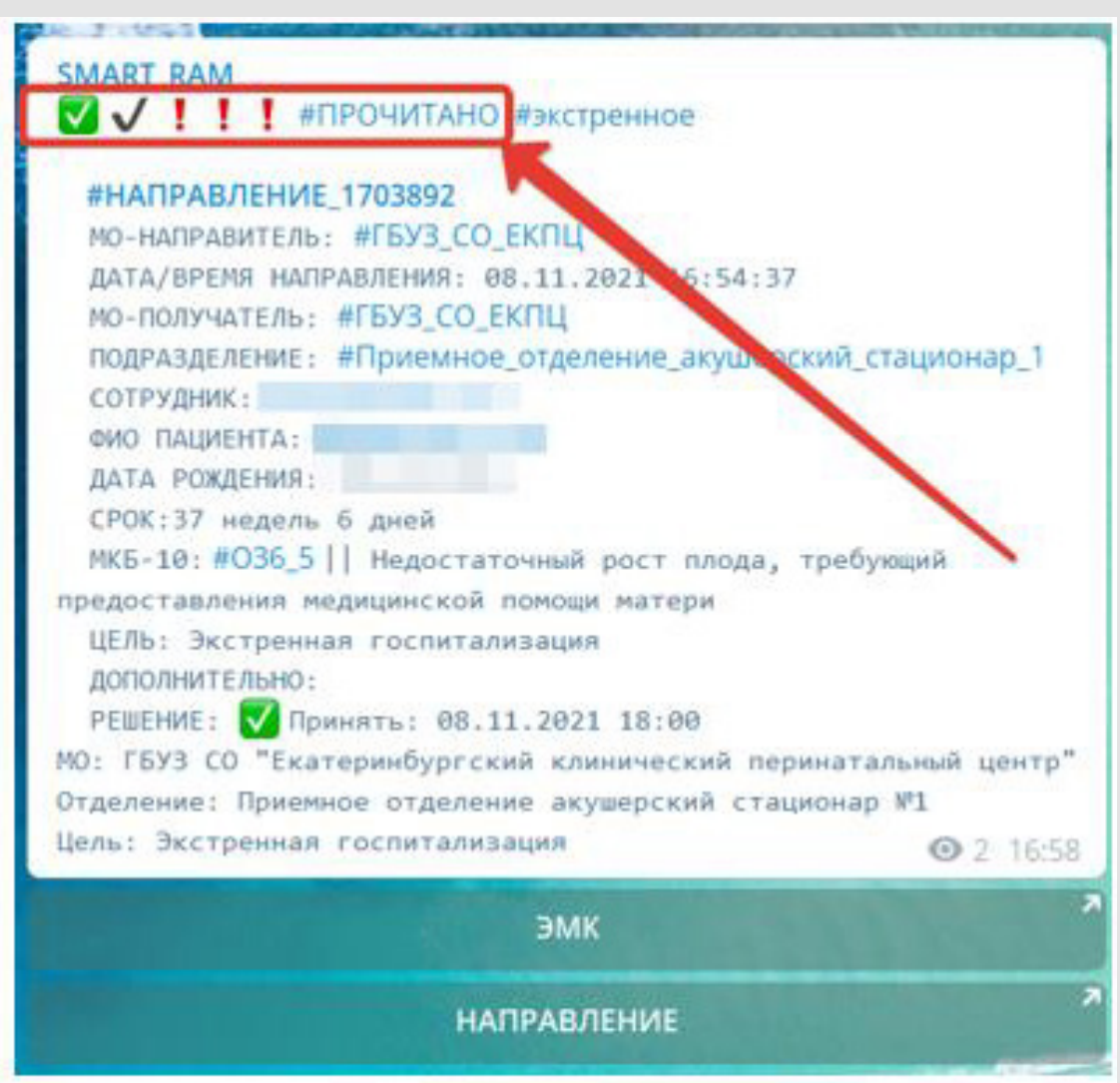

Figure 9: Communication with the patient through confidential "working" chat in AIST_SMART.

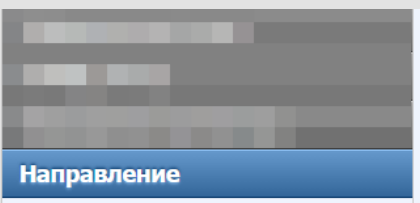

Уведомления

th Н Направленные

На исполнение

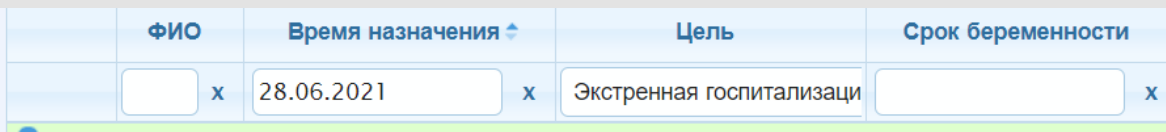

- Приемное отделение акушерский стационар №1 (1).

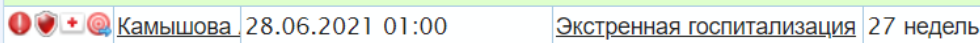

фобновить

Figure 10: Patient admission sheet in obstetric hospital.

\section{You do not Need to Receive a Paper Direction}

If necessary, you can print the direction at the place of treatment of the patient, using a single information space of the regional obstetric monitoring of AIST "RAM". All the directions that a woman received during pregnancy are reflected in her personal account in the "My directions" section. The patient can open any document, even if the connection with the Internet has disappeared.

\section{Advantages of Remote Monitoring of Health}

The transition to electronic diaries of self-control allows you to identify complications of the gestational process in the case of arterial hypertension and timely send the patient to hospitalization to prevent adverse events, which is from the main directions of the quality management system and safety of medical care. AIST_ SMART allows you to create constant feedback with the patient and thereby form a patient-centric model of care as one of the priority areas for the development of modern medicine and healthcare in general. All of the above increases the compliance of doctor-patient interaction and directly affects the quality and safety of medical care in the context of the widespread prevalence of arterial hypertension in the population (pregnant women are no exception), which meets modern needs of society and solves the tasks set by the Government 
of the Russian Federation in the field of digitalization of healthcare [3-5].

\section{Conflict of Interest}

No conflict of interest with any institution/organization.

\section{References}

1. Federal Law of 21.11.2011 No. 323-FZ "On the Basics of Protecting the Health of Citizens in the Russian Federation".

2. Clinical recommendations of the Ministry of Health of Russia "Preeclampsia. Eclampsia. Edema, proteinuria and hypertensive

ISSN: 2574-1241

DOI: 10.26717/BJSTR.2021.39.006378

Nikolay O Ankudinov. Biomed J Sci \& Tech Res

(c) (P) This work is licensed under Creative

Submission Link: https://biomedres.us/submit-manuscript.php disorders during pregnancy, childbirth and the postpartum period" 2021.

3. https://www.zdrav.ru/articles/4293663431-lichnyy-kabinetaistsmartdlya-beremennyh-i-vrachey-s-mobilnymi-21-m10-20-qqqzg21.

4. Order of the Ministry of Health of the Russian Federation No. $965 \mathrm{n}$ dated 30.11.2017 "On approval of the procedure for the organization and provision of medical care using telemedicine technologies".

5. https://smarteka.com/practices/licnyj-kabinet-aist-smart-smobilnymi-uvedomleniami.

$\begin{array}{ll}\text { BIOMEDICAL } & \text { Assets of Publishing with us } \\ \text { RESEARCHES } & \text { - Global archiving of articles } \\ & \text { - Immediate, unrestricted online access } \\ & \text { - Rigorous Peer Review Process } \\ & \text { - Authors Retain Copyrights }\end{array}$

